\title{
Novos táxons em Elaphidionini (Cerambycinae) e Onciderini (Lamiinae) e novos registros em Cerambycidae
}

\author{
Maria Helena M. Galileo ${ }^{1,3}$ \& Ubirajara R. Martins s,3 $^{2,3}$
}

${ }^{1}$ Museu de Ciências Naturais, Fundação Zoobotânica do Rio Grande do Sul. Caixa Postal 1188, 90001-970 Porto Alegre-RS, Brasil.
${ }^{2}$ Museu de Zoologia, Universidade de São Paulo. Caixa Postal 42494, 04218-970 São Paulo-SP, Brasil.
${ }^{3}$ Pesquisador do CNPq.

\begin{abstract}
New taxa in Elaphidionini (Cerambycinae) and Onciderini (Lamiinae) and new records in Cerambycidae. Based on material of the Universidade Estadual do Norte Fluminense (Museu de Entomologia), two new taxa are described in Cerambycinae, Elaphidionini: Magaliella gen. nov., type-species, M. punctata sp. nov. (Espírito Santo) and in Lamiinae, Onciderini: Oncideres hoffmanni sp. nov. (Bahia). New records for Brasil are: Potiaxixa intermedia (Martins, 1979) (Bahia); Appula melancholica Gounelle, 1909 (Distrito Federal), Pseudogisostola reichardti Fontes \& Martins, 1977 (Rio de Janeiro), Hesycha bimaculata Martins \& Galileo, 1990 (Bahia) and Xenofrea apicalis Melzer, 1931 (Rio de Janeiro).
\end{abstract}

KEYWORDS. Neotropical; new species; taxonomy.

RESUMO. Novos táxons em Elaphidionini (Cerambycinae) e Onciderini (Lamiinae) e novos registros em Cerambycidae. Fundamentados em material da Universidade Estadual do Norte Fluminense (Museu de Entomologia), descreve-se em Cerambycinae, Elaphidionini: Magaliella gen. nov., espécie-tipo, M. punctata sp. nov. (Espírito Santo) e em Lamiinae, Onciderini: Oncideres hoffmanni sp. nov. (Bahia). Acrescentam-se novos registros para o Brasil: Potiaxixa intermedia (Martins, 1979) (Bahia); Appula melancholica Gounelle, 1909 (Distrito Federal), Pseudogisostola reichardti Fontes \& Martins, 1977 (Rio de Janeiro), Hesycha bimaculata Martins \& Galileo, 1990 (Bahia) e .Xenofrea apicalis Melzer, 1931 (Rio de Janeiro).

PALAVRAS-CHAVE. Neotropical; novas espécies; taxonomia.

Foi-nos remetida para estudo, pela Dra. Magali Hoffmann, uma coleção de Cerambycidae da Universidade Estadual do Norte Fluminense, Centro de Ciências e Tecnologias Agropecuárias, Setor de Entomologia, Campos dos Goytacazes, Rio de Janeiro.

Essa coleção reúne cerca 50.000 insetos, principalmente exemplares da Bahia, do Espírito Santo e do Rio de Janeiro. Salientamos dentre o material estudado, espécies de Cerambycidae, que nos facultam apresentar registros inéditos e descrever novos táxons em Elaphidionini (Cerambycinae) e em Onciderini (Lamiinae).

Elaphidionini foi revista recentemente por Martins (2005) e reúne cerca de 50 gêneros na América do Sul. O gênero novo, Magaliella, pertence a um pequeno agrupamento de gêneros com élitros recobertos por pubescência serícea que forma desenhos mutáveis conforme a incidência da luz.

Onciderini foi revista por Dillon \& Dillon (1945, 1946), mas muitas contribuições posteriores foram publicadas. A nova espécie pertence ao gênero Oncideres Lepeletier \& AudinetServille, 1830 que reúne 109 espécies (Monné 2005b).

As siglas das instituições citadas no texto são: MCNZ, Museu de Ciências Naturais, Fundação Zoobotânica do Rio Grande do Sul, Porto Alegre; UENF, Universidade Estadual do Norte Fluminense, Campos dos Goytacazes.

\section{CERAMBYCINAE \\ Cerambycini}

Potiaxixa intermedia (Martins, 1979)

Brasilianus intermedius Martins, 1979: 27.

Potiaxixa intermedia; Martins \& Monné, 2002: 223; Monné, 2005a: 59 (cat.)

Até agora conhecida apenas do Estado de São Paulo.

Material examinado. BRASIL, Bahia: Camaçari (Reserva da Serra Bonita), fêmea, 3-8.X.2005, E. A. Silva col. (MCNZ, doação de M. Hoffmann).

\section{Elaphidionini}

\section{Appula melancholica Gounelle, 1909}

Appula melancholica Gounelle, 1909: 650; Monné, 2005a: 200 (cat.).

Já registrada no Brasil, para os estados de Pará, Rondônia, Mato Grosso e Goiás, na Bolívia e no Paraguai.

Material examinado. BRASIL, Distrito Federal: Brasília, macho, 22.X.2003. M. J. Tauber \& C. A. Tauber col. (UENF). 


\section{Magaliella gen. nov.}

Espécie-tipo, Magaliella punctata $\mathbf{s p . ~ n o v . ~}$

Fronte transversal. Sutura fronto-clipeal curva. Sutura coronal prolongada até entre os tubérculos anteníferos. Olhos sem pêlos entre os omatídios; não adelgaçados entre os lobos. Lobos oculares superiores com cinco fileiras de omatídios; mais distantes entre si que o dobro da largura de um lobo. Lobos oculares inferiores atingem a face ventral da cabeça. Genas com o ápice espinhoso. Tubérculos anteníferos com ápice projetado. Antenas com onze artículos; nos machos, atingem a ponta dos élitros na base do antenômero VII. Escapo pouco e gradualmente engrossado para a extremidade; indistintamente sulcado na base e densamente pontuado; comprimento apenas maior que a metade do antenômero III. Antenômeros III-VIII densamente providos de pêlos. Antenômero III sem carena, apenas mais longo do que o seguinte e com espículo no ápice interno. Antenômeros IV e V com comprimentos subiguais e espículo no ápice interno (20x).

Protórax com espinho lateral desenvolvido. Lados da região látero-anterior do pronoto com sulco profundo; pronoto com quatro gibosidades pouco manifestas. Largura do processo prosternal igual a um quarto daquela da procoxa. Processo mesosternal entalhado no ápice e mais largo que metade da mesocoxa. Cavidades coxais anteriores angulosas no lado externo. Cavidades mesocoxais abertas. Sutura metasternal completa. Élitros revestidos por pubescência serícea entremeada por pontos contrastantes e ásperos. Extremidades elitrais cortadas em curva com espinho curto no lado externo.

Fêmures fusiformes, desarmados na extremidade. Ápice dos metafêmures não atinge a ponta dos élitros. Metatíbias sem carenas. Metatarsômero I com o dobro do comprimento de II+III.

Discussão. Na chave para os gêneros sul-americanos de Elaphidionini (Martins 2005), Magaliella gen. nov. é discriminado junto com os que têm "élitros com área de pubescência serícea densa que conforme a incidência da luz, formam desenhos que contrastam com o fundo acastanhado ou preto". Pela presença de espinho nos lados do protórax, assemelha-se à Mallocera Audinet-Serville, 1833 do qual difere pelas genas espinhosas no ápice, pelo escapo robusto, pelo antenômero III sem carena e sem espinho desenvolvido no ápice, pelos élitros com pontos pilíferos grandes, ásperos e contrastantes e pelos fêmures fusiformes.

Etimologia. O nome genérico é em homenagem à Dra. Magali Hoffmann, curadora da coleção entomológica da UENF.

\section{Magaliella punctata sp. nov.} (Fig. 1)

Cabeça, escapo, pedicelo, protórax, élitros e face ventral do corpo, acastanhados. Flagelômeros e pernas, amarelados. Cabeça e pronoto revestidos por pubescência dourada.
Élitros cobertos por pubescência serícea com reflexos esverdeados; quando a cabeça do inseto está voltada para a fonte luminosa, aparecem duas áreas acastanhadas, oblíquas: uma no meio da metade anterior e a outra depois do meio dos élitros.

Fêmures e face ventral revestidos por pubescência dourada.

Dimensões, em mm, holótipo macho. Comprimento total, 19,4; comprimento do protórax, 3,5; maior largura do protórax, 4,3; comprimento do élitro, 13,5; largura umeral, 4,4.

Material-tipo. Holótipo macho, BRASIL. Espírito Santo: Linhares (Reserva Natural do Vale do Rio Doce), 17.IV.2004, G. S. Albuquerque col. (MCNZ, doação de M. Hoffmann).

\section{LAMIINAE \\ Falsamblesthiini}

Pseudogisostola reichardti Fontes \& Martins, 1977

Pseudogisostola reichardti Fontes \& Martins, 1977: 13, figs. 3-5; Monné, 2005b: 437 (cat.); Wappes et al., 2006: 42 (distr.).

Distribuição. Brasil, Espírito Santo e Bolívia.

Material examinado. BRASIL, Rio de Janeiro: Conceição de Macabú (Hotel Fazenda Carrapeta), fêmea, 6.XI.2002, G. S. Albuquerque col. (MCNZ, doação de M. Hoffmann).

\section{Onciderini}

Hesycha bimaculata Martins \& Galileo, 1990

Hesycha bimaculata Martins \& Galileo, 1990: 76, fig. 34; Monné, 2005b: 551 (cat.).

Distribuição. Registrada para o Espírito Santo, Brasil.

Material examinado. BRASIL, Bahia: Camaçari (Reserva da Serra Bonita, 800 m), fêmea, 4-6.X.2005, C. A. Tauber (MCNZ, doação de M. Hoffmann).

\section{Oncideres hoffmanni sp. nov.}

(Fig. 2)

Cabeça revestida por pubescência alaranjada. Região central da fronte com alguns pontos pequenos. Lobos oculares inferiores com o dobro do comprimento das genas. Vértice com poucos pontos ao lado dos lobos oculares superiores. Tubérculos anteníferos muito projetados. Antenas atingem o ápice dos élitros aproximadamente no meio do antenômero VIII. Escapo, pedicelo, antenômeros III e IV pretos; V a XI gradualmente mais avermelhados. Antenômero III engrossado, subcilíndrico.

Protórax curto, revestido por pubescência predominantemente alaranjada. Espinho lateral acuminado e situado no terço posterior. Centro do pronoto com apenas algumas rugosidades rasas e transversais. Lados do pronoto, 

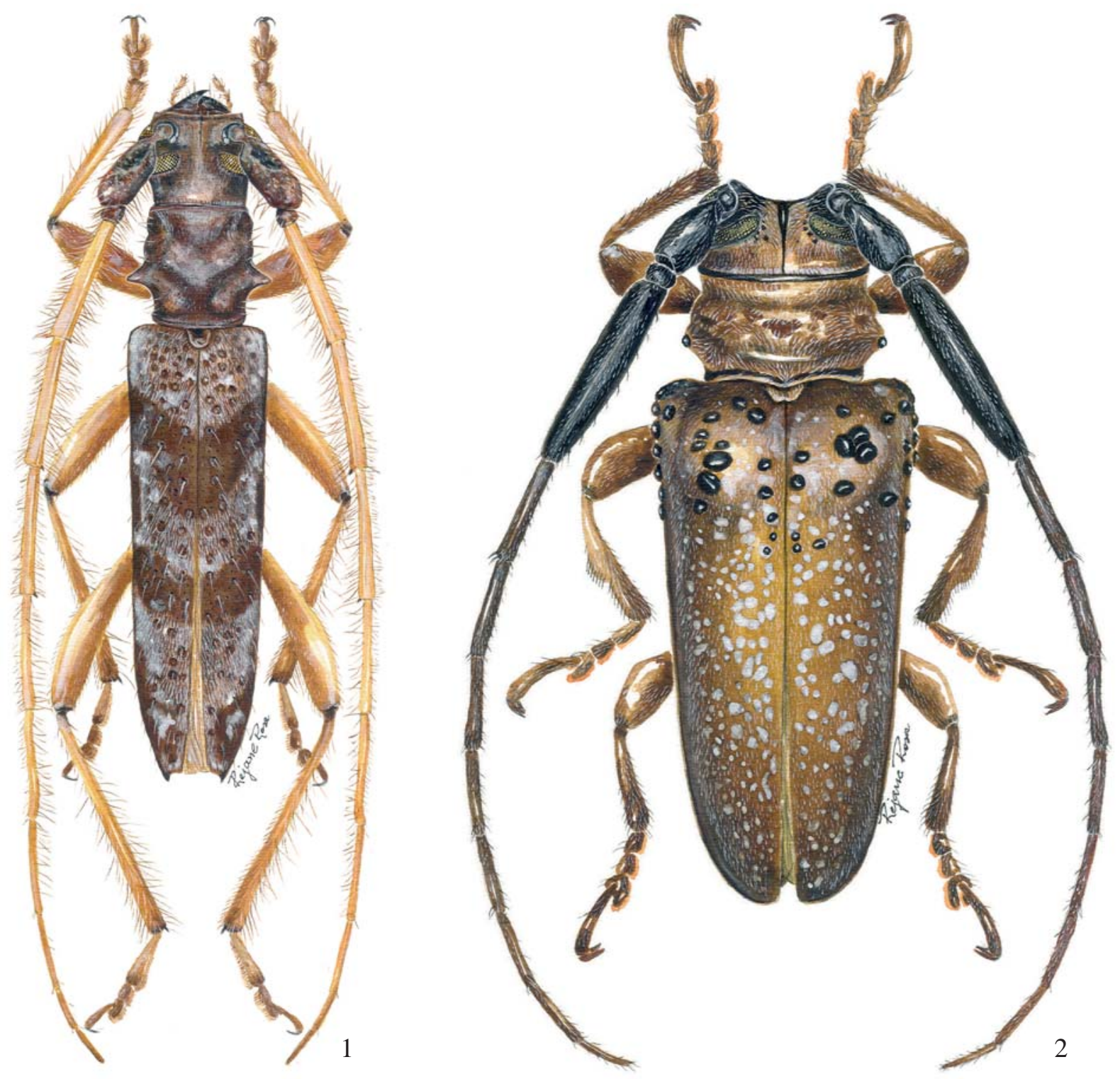

Figs. 1-2. Habitus. 1, Magaliella punctata sp. nov., holótipo macho, comprimento, 19,4 mm; 2, Oncideres hoffmanni sp. nov., holótipo macho, comprimento, $14,3 \mathrm{~mm}$.

adiante dos espinhos laterais, com pequena mancha glabra. Escutelo revestido por pubescência alaranjada.

Quarto basal dos élitros com tubérculos pretos, grandes e glabros. Da região posterior dos tubérculos até antes do meio dos élitros, a pubescência alaranjada está entremeada por máculas esparsas de pubescência branca; do meio para o ápice, pubescência alaranjada entremeada por inúmeras máculas pequenas de pubescência branca.

Fêmures com o lado ventral coberto de pubescência branca e o dorsal revestido por pubescência alaranjada. Prosterno, mesosterno e centro do metasterno revestidos por pubescência branca. Mesepisternos e mesepimeros com pubescência alaranjada. Lados do metasterno com pubescência alaranjada entremeada por pubescência branca. Metepisternos cobertos por pubescência predominantemente alaranjada.
Dimensões, em mm, holótipo macho. Comprimento total, 14,3; comprimento do protórax, 2,0; maior largura do protórax, 4,2; comprimento do élitro, 11,0; largura umeral, 5,2.

Material-tipo. Holótipo macho, BRASIL, Bahia: Camaçari (Reserva da Serra Bonita, 800 m), 4-6.X.2005, M. J. Tauber col. (MCNZ, doação de M.Hoffmann).

Discussão. Oncideres hoffmanni sp. nov. assemelha-se a Oncideres etiolata Dillon \& Dillon, 1946, mas difere pelos lobos oculares inferiores com o dobro do comprimento das genas (vide descrição); pelo protórax mais curto, praticamente sem rugas transversais e com espinho lateral mais desenvolvido; pelos grânulos maiores na base dos élitros; pelas procoxas do macho não projetadas; pelos profêmures dos machos sem rugosidades; pela pubescência branca 
entremeada à pubescência alaranjada nos lados do metasterno. Em O. etiolata os lobos oculares inferiores são apenas mais longos que as genas, o protórax é mais longo e transversalmente rugoso, inclusive nas partes laterais, com tubérculo lateral pequeno, os grânulos da base dos élitros são menores e mais esparsos, as procoxas do macho são projetadas, os profêmures são fortemente rugosos no lado externo e o metasterno é revestido por pubescência alaranjada.

Etimologia. O epíteto é uma homenagem à Dra. Magali Hoffmann.

\section{Xenofreini}

\section{Xenofrea apicalis Melzer, 1931}

Xenofrea apicalis Melzer, 1931: 3, fig. 4; Monné, 2005b: 662 (cat.).

Distribuição. Guiana Francesa, Brasil (Minas Gerais, Santa Catarina) e Paraguai.

Material examinado. BRASIL, Rio de Janeiro: Conceição de Macabú (Hotel Fazenda Carrapeta), fêmea, 30.IV.2003, E. A. Silva col. (UENF).

Agradecimentos. À desenhista Rejane Rosa (MCNZ) pelas ilustrações.

\section{REFERENCIAS}

Dillon, L. S. \& E. S. Dillon. 1945. The tribe Onciderini (Coleoptera: Cerambycidae) Part I. Scientific Publications of the Reading Public Museum 5: 1-186, xv p.

Dillon, L. S. \& E. S. Dillon. 1946. The tribe Onciderini (Coleoptera: Cerambycidae) Part II. Scientific Publications of the Reading Public Museum 6: 189-413.

Fontes, L. R. \& U. R. Martins. 1977. Novos Hebestolini (Coleoptera, Cerambycidae, Lamiinae) do Brasil. Revista Brasileira de Entomologia 21: 7-14.

Gounelle, E. 1909. Liste des cérambycides de la région de Jatahy, Etat de Goyaz, Brésil. Annales de la Société Entomologique de France 77: 587-688

Martins, U. R. 1979. Notas e descrições em Brasilianus Jakobson, 1924 (Coleoptera, Cerambycidae). Revista Brasileira de Entomologia 23: 23-28.

Martins, U. R. 2005. Cerambycidae sul-americanos. Taxonomia, Subfamília Cerambycinae: Elaphidionini. São Paulo, Sociedade Brasileira de Entomologia. v. 7, 394 p.

Martins, U. R. \& M. H. M. Galileo. 1990. Onciderini: (Coleoptera, Cerambycidae, Lamiinae) sinonímias, novos táxons, chaves e notas. Papéis Avulsos de Zoologia 37: 53-95.

Martins, U. R. \& M. A. Monné. 2002. Tribo Cerambycini, p. 145-248. In: U. R. Martins (ed). Cerambycidae Sul-Americanos. Taxonomia. São Paulo, Sociedade Brasileira de Entomologia. v. 4, $265 \mathrm{p}$.

Melzer, J. 1931. Cerambycideos neotrópicos, principalmente do Brasil. Revista de Entomologia 1: 1-15.

Monné, M. A. 2005a. Catalogue of the Cerambycidae (Coleoptera) of the Neotropical Region. Part I. Subfamily Cerambycinae. Zootaxa 946: $1-765$.

Monné, M. A. 2005b. Catalogue of the Cerambycidae (Coleoptera) of the Neotropical Region. Part II. Subfamily Lamiinae. Zootaxa 1023: $1-760$.

Wappes, J. E.; R. F. Morris; E. H. Nearns \& M. C. Thomas. 2006. Preliminary checklist of Bolivian Cerambycidae (Coleoptera). Insecta Mundi 20: 1-45. 